\title{
frontiers
}

FOR YOUNG MINDS

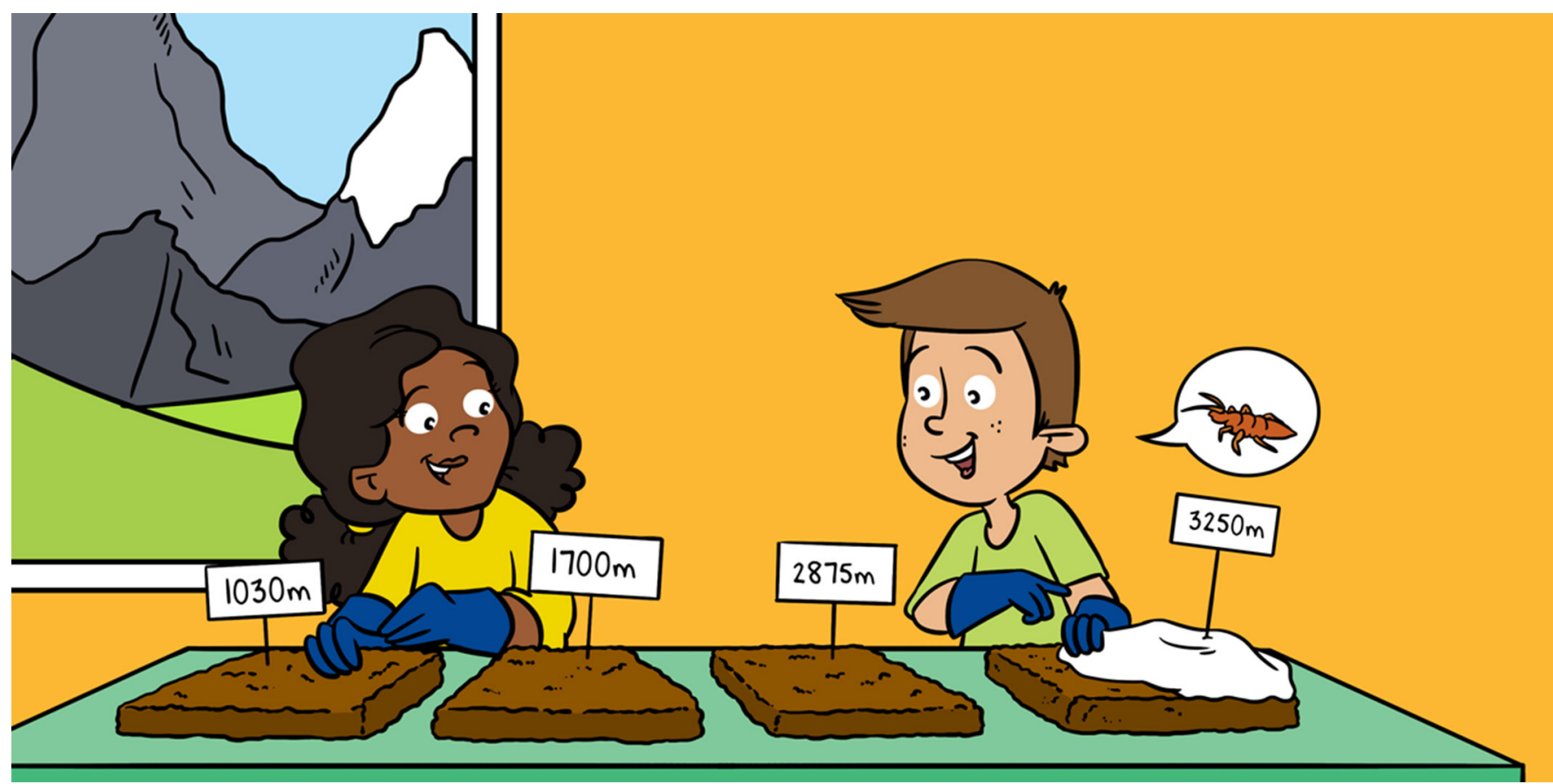

\section{BELOWGROUND MOUNTAINEERS: CRITTERS LIVING IN MOUNTAIN SOILS}

\author{
Michael Steinwandter ${ }^{1 *}$ and Julia Seeber ${ }^{1,2}$ \\ ${ }^{1}$ AlpSoil Lab, Institute for Alpine Environment, Eurac Research, Bozen, Italy \\ ${ }^{2}$ Department of Ecology, University of Innsbruck, Innsbruck, Austria
}

YOUNG REVIEWERS: MERCY SCHOOL INSTITUTE AGES: 15
The soil beneath our feet still requires more exploration, although we know that it is home to a vast number of organisms. It is basically a black box we cannot see into to observe its inhabitants and the processes they contribute to. In this article, we will tell you about soils that are even less explored. We are talking about mountain soils at high elevation: they are not easily accessible but harbor many exciting species, some of which are specialized to live only in mountain soils. We are a team of soil ecologists who dedicate our research to revealing the secrets of animals living in mountain soils. We will tell you which and how many soil critters can be found in high-elevation soils of the European Alps, in both natural mountain ecosystems and those used for farming. Further, we explain some clever ways these species have adapted to the harsh alpine environment. 


\section{ALPINE ZONE}

A climatic zone that can be found in higher mountains or arctic areas. It is the zone where tree cannot grow because of the low temperatures.

\section{INVERTEBRATES}

A large group of animals that have no vertebrae (backbones). Common soil invertebrates include insects (beetles, fly larvae), earthworms, millipedes, centipedes, woodlice, and spiders.

\section{KEMPSON}

APPARATUS

A device in soil laboratories for extracting animals from soil blocks. Being heated from above, soil animals seek to escape the dry and hot conditions and fall into a collection bucket.

\section{PITFALL TRAP}

A simple method to catch ground-dwelling insects and invertebrates. These are glass jars that are dug into the soil and are left active for one or several days.

\section{SUBALPINE ZONE}

A climatic zone that includes the mountain forests up to the natural treeline. It includes also a transition zone between these forests and the alpine grassland where only small shrubs and single trees can grow.

\section{WHAT ARE MOUNTAIN SOILS?}

When we talk about mountain soils, we usually refer to soils at high elevation, particularly soils above the treeline where there are only scattered trees, or no trees at all. In the European Alps, this zone can be found above 2,000 m; in the Central European Alps, above 2,300 m. Of course, some mountain soils are found on lower mountains or even hills, but we will focus on the beautiful world of soil animals that live in natural grasslands, grazed pastures, and even bare soils on higher mountains like the European Alps, from 1,500 to 3,000 m.

Some mountain areas above the treeline, in what is called the alpine zone, may seem to be untouched by humans. But this is not true-farmers have gently used many such grasslands for centuries and even millennia, as pastures for small stocks of cows, sheep, and goats in the summer months (Figure 1A). Why did farmers of the past (and some even today) hike up so far with cows and sheep? Why not just use the meadows in the valley bottom, which are easily accessible? Well, they do use the valley meadows, but the alpine pastures are home to many colorful and nutritious herbs and grasses that cows and sheep love to eat and which are very healthy for them. Also, during hot summers, the temperatures at higher elevations are much more bearable for the animals.

\section{WHICH AND HOW MANY ANIMALS LIVE IN MOUNTAIN SOILS?}

The beauty of mountains lies not only aboveground in the colorful flowers and shrubs, but also beneath our feet. To study the soil critters, we remove square soil blocks of $20 \times 20$ and $15 \mathrm{~cm}$ deep (Figure $1 \mathrm{C}$ ) and extract the invertebrates using a Kempson apparatus. The Kempson apparatus uses heat and light from lightbulbs to force the animals to escape from the soil as the blocks dry out. The animals are then collected from water-cooled buckets containing a collection fluid. Further, we also install pitfall traps in our study locations (Figure 1B). Pitfall traps are open glass jars, dug into the ground so that organisms like spiders and beetles will fall into them and be trapped. This is a very useful method to see what is crawling on the soil surface. Using these techniques, we found a diverse community of earthworms, millipedes, beetles, and insect larvae in mountain soils.

Soil biodiversity is especially high in the subalpine zone, from 1,500 to $2,000 \mathrm{~m}$. This border area contains forests and manmade pastures. In this zone, soil animals typically found in mountain forests (such as woodlice and centipedes) co-exist with species from natural grasslands (earthworms and millipedes). In subalpine pastures in the Central European Alps, we found up to 115 earthworms per square metre in the upper $15 \mathrm{~cm}$ of the soil layer, as well as 60 millipedes, 
Figure 1

In the European Alps, centuries of traditional farming created species-rich grassland soils. (A) The alpine zone above the treeline is often grazed by cows and sheep. Below in the subalpine zone, forests were also cut down to create pastures and hay meadows. Rocky areas increase at higher elevations and are dominant in the high alpine, which is the area above most vegetation (Gsies/Valle di Casies, South Tyrol, Italy). (B) We assess soil invertebrates by installing pitfall traps (yellow arrow) (Dolomites, South Tyrol, Italy). (C) Soil blocks are removed and taken to the laboratory to be studied (Matsch/Mazia, South Tyrol, Italy) (Photograph credits: Michael Steinwandter).

\section{NIVAL ZONE}

A rocky and often snow-covered area of high mountains and arctic regions that follows the alpine zone. Here, almost no plants grow, but mostly lichens and mosses.

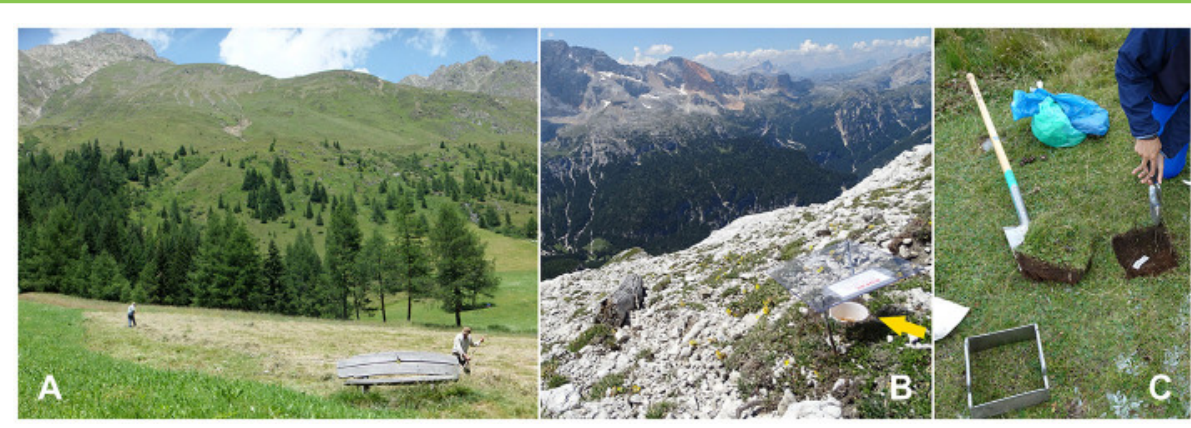

Figure 1

55 beetles, and 50 larvae of flies and midges [1]. All these soil invertebrates profit from the sporadic presence of animals that roam the fields, including cows, sheep, and wild mammals such as deer, chamois, and Alpine ibex. The grazing animals keep the vegetation short, remove troublesome shrubs, and therefore keep the grasslands open. Additionally, they leave behind lots of dung, which is a welcome food source for many soil animals such as earthworms, millipedes, and dung beetles (Figure 2) [2]. However, if farmers bring too many cows and sheep up to these areas, we can observe negative effects of trampling and too much dung, which results in reduced numbers of some types of soil animals. For example, we found only about 5 specimens of millipedes and 45 beetles per square metre in an area that was overused by farmers.

The higher we go, the fewer individuals and types of soil animals we find (Figure 3). In the alpine zone, from 2,000 to 2,800 m, trees cannot grow because temperatures are too low and the summer growing season is short. In this alpine zone, some types of soil animals reach the upper limit of their comfort zone. Earthworms and millipedes decrease in numbers and can rarely be found at elevations above 2,500 m, even if roaming sheep add extra food in the form of dung. We found only 20 earthworms and 10 millipedes per square metre in the alpine zones we studied. On the other hand, fly and midge larvae increase massively in numbers (more than 750 per square metre) and partly take over the important ecosystem functions of earthworms, such as the breakdown of dead plant material [3].

In the European Alps, areas above $2,500 \mathrm{~m}$ are often covered with snow for much of the time, making life very challenging for soil animals. These zones, called the high alpine zone and the nival zone (above $3,000 \mathrm{~m}$ ), are usually not used by farmers. These areas are inhabited mainly by small soil animals such as springtails and mites. These cold-weather specialists survive beneath the snow cover, which acts like a blanket to keep temperatures slightly above freezing, even when the air temperature falls well-below freezing. 
Figure 2

Mountain soil

invertebrates from our research sites in the

Stubai Alps and Oetztal

Alps in Tyrol, Austria. (A)

A lifted cowpat unveils

the feeding burrows of earthworms (Lumbricus rubellus), dung beetles, and insect larvae. (B)

The pill millipede (Glomeris transalpina) is commonly found in alpine shrubland in the Central European Alps. (C) Larvae of fungus gnats (Mycetophilidae) feed on sheep dung in high alpine pastures (Photograph credits: Michael Steinwandter).

\section{ADAPTATION}

The ability to adapt to new environmental conditions by optimising body characteristics and/or behaviour. For example, alpine invertebrates adapted to the harsh mountain environment.

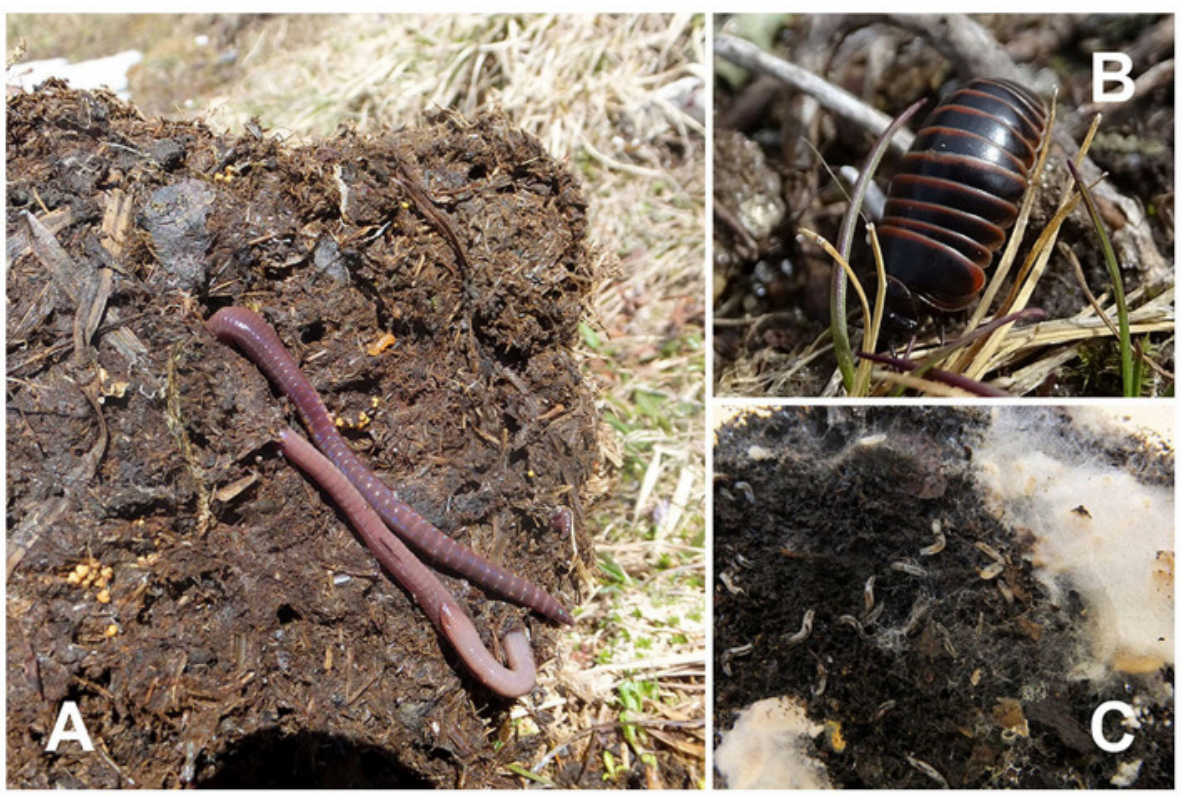

Figure 2

\section{HOW CAN THESE ANIMALS SURVIVE?}

Adaptation is key to survival at high elevations. Adaptation is the ability to adapt to new environmental conditions by optimising body characteristics and/or behaviour. Soil animals in these ecosystems experience low temperatures and often encounter snow even in the summer months. They also face stronger sun rays and less and less living space the higher the elevation. These animals cannot be picky about what they eat-they must feed on any available food sources. For example, while in lowlands some beetles feed on plant-based food only, in alpine pastures they also feed on other animals and their shed-off skins or carcasses, as well as on dung, if it is present [4]. The adaptation to this broader menu increases the chances that these beetles will successfully gather enough energy to survive and thrive.

Another survival strategy of mountain soil animals is that they can prolong their life stages if the summers are too short to allow them to reach the next stage. For example, during a snowy, cold summer when a millipede cannot get enough energy to produce its eggs, it can wait another season and produce eggs the following year when the conditions are more favourable. While this is a useful adaptation, it also means that these millipedes must survive longer in the harsh environment to successfully finish their egg production.

Soil animals at high elevations have also adapted their bodies to the harsh conditions by decreasing their body size (smaller bodies can heat up more easily), by losing their wings (without wings the animals can stay close to the soil surface and avoid strong winds), by changing their body colours (darker bodies can heat up more easily), or/and 
Figure 3

Distribution of typical soil invertebrates at the various elevation zones of the Central European Alps. The zones start and end at different elevations on the sunny side and the shady side. The table shows how many animals per square metre can be expected at each elevation zone, based on currently available data.

Generally, the number of soil animals is decreasing with increasing elevation, with different animal groups reaching their limit at different elevations (such as millipedes at 2,500 m, beetles at 3,000 m). Asterisks $\left({ }^{*}\right)$ indicate that very limited, highly variable data are available (Image credits: modified after Wikimedia Commons).

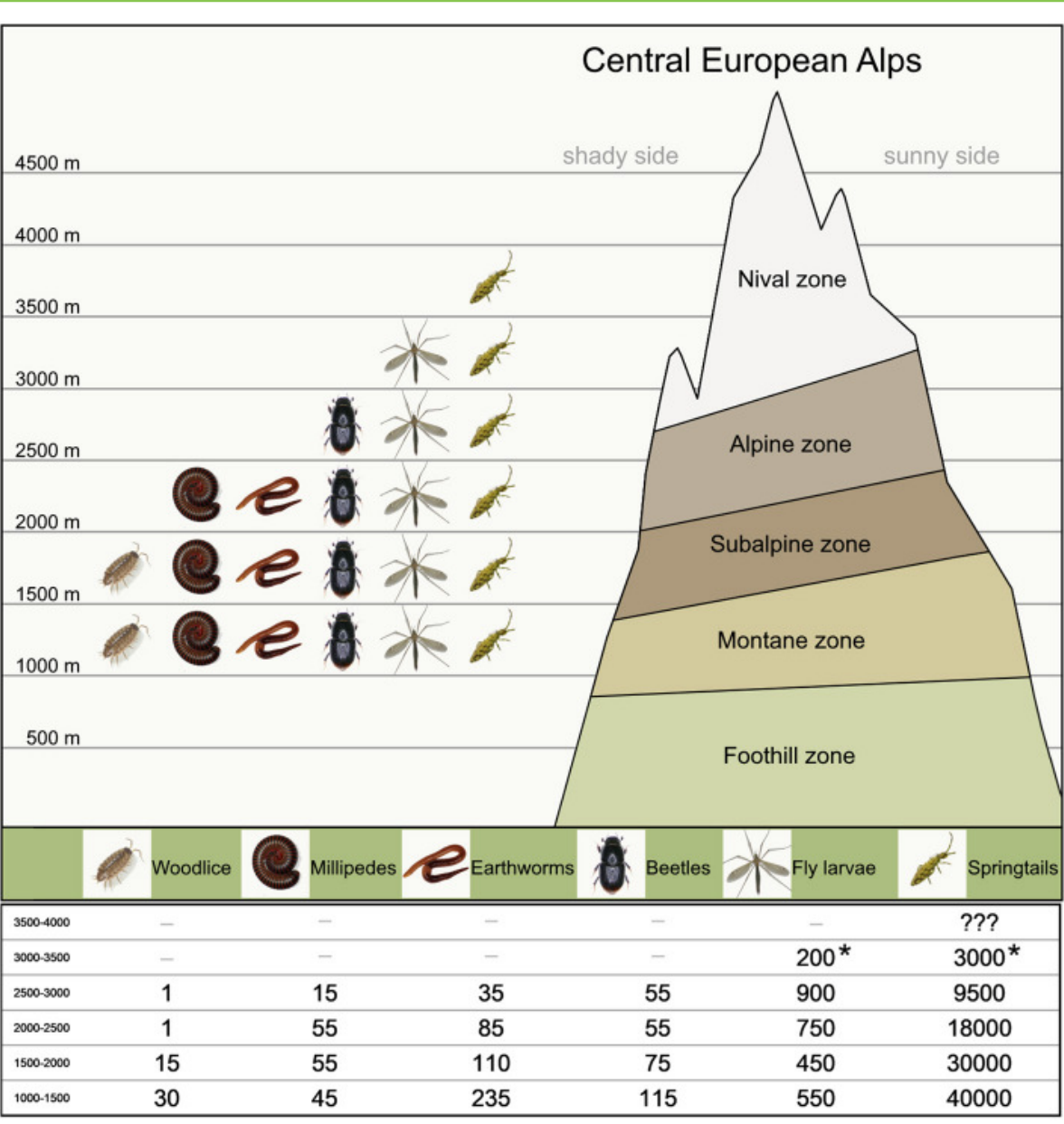

Figure 3

by producing anti-freeze in their bodies, to prevent their bodies from freezing at low temperatures.

\section{DO MOUNTAIN SOILS NEED HELP?}

Now you know that mountain soils are interesting places that are home to many soil invertebrates, some of which can only be found in mountain soils. Because these soils and their inhabitants are still understudied, the possibility of finding new species there is quite high. However, like many ecosystems nowadays, mountain soils are threatened and need to be protected. One big problem that species-rich subalpine pastures face is that farmers are abandoning these lands, because these traditional methods of farming do not generate enough money. When cows and sheep are no longer grazing the alpine grasslands at the treeline, these areas will be taken over by persistent shrubs that form dense and unpassable shrubland. Also, the increasing temperatures resulting from climate change will lead to an upwards migration of soil animals, as they try to escape temperatures that are too warm for them. But because there is less and less space as the elevation increases, these animals will have problems 
finding enough room to live, and they might experience a higher risk of extinction.

But the good news is that we can all help! For instance, by supporting mountain farmers and buying their products (like milk and cheese) we can increase the chances that they can continue to maintain beautiful alpine pastures. Further, we can personally take care of mountain soils by not damaging them when we go hiking, mountaineering, or skiing. We should stay on the trails and take our trash back home instead of leaving it in the mountains. Lastly, we can take political action, by raising our voices against the building of new entertainment facilities such as ski areas, mountain huts, and mountain bike trails, which can harm these natural and sensitive areas.

We all need to be extremely careful with this precious ecosystem called soil. Let us keep in mind that mountain soils needed centuries - and in high mountains, even millennia-to form, but these ecosystems and the fascinating soil organisms that live there can be destroyed in minutes, without our protection!

\section{REFERENCES}

1. Steinwandter, M., Schlick-Steiner, B. C., Seeber, G. U. H., Steiner, F. M., and Seeber, J. 2017. Effects of Alpine land-use changes: soil macrofauna community revisited. Ecol. Evolut. 7:5389-99. doi: 10.1002/ece3.3043

2. Curry, J. P., and Schmidt, O. 2007. The feeding ecology of earthworms-a review. Pedobiologia. 50:463-77. doi: 10.1016/j.pedobi.2006.09.001

3. Kitz, F., Steinwandter, M., Traugott, M., and Seeber, J. 2015. Increased decomposer diversity accelerates and potentially stabilises litter decomposition. Soil Biol. Biochem. 83:138-41. doi: 10.1016/j.soilbio.2015.01.026

4. Steinwandter, M., Rief, A., Scheu, S., Traugott, M., and Seeber, J. 2018. Structural and functional characteristics of high alpine soil macro-invertebrate communities. Euro. J. Soil Biol. 86:72-80. doi: 10.1016/j.ejsobi.2018.03.006

SUBMITTED: 28 January 2021; ACCEPTED: 07 January 2022; PUBLISHED ONLINE: 03 February 2022.

EDITOR: Malte Jochum, German Centre for Integrative Biodiversity Research (iDiv), Germany

SCIENCE MENTOR: Fares Z. Najar

CITATION: Steinwandter M and Seeber J (2022) Belowground Mountaineers: Critters Living in Mountain Soils. Front. Young Minds 10:660110. doi: 10.3389/frym. 2022.660110

CONFLICT OF INTEREST: The authors declare that the research was conducted in the absence of any commercial or financial relationships that could be construed 
as a potential conflict of interest

COPYRIGHT (c) 2022 Steinwandter and Seeber. This is an open-access article distributed under the terms of the Creative Commons Attribution License (CC BY). The use, distribution or reproduction in other forums is permitted, provided the original author(s) and the copyright owner(s) are credited and that the original publication in this journal is cited, in accordance with accepted academic practice. No use, distribution or reproduction is permitted which does not comply with these terms.

\section{YOUNG REVIEWERS}

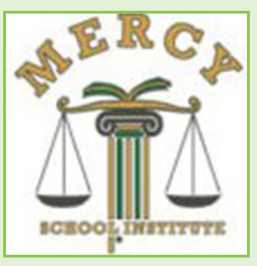

\section{MERCY SCHOOL INSTITUTE, AGE: 15}

We are fun and dynamic leaders, and we love to hang out with our friends.
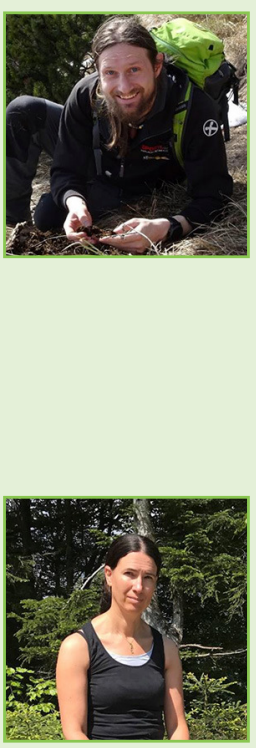

\section{AUTHORS}

\section{MICHAEL STEINWANDTER}

I am a soil ecologist and soil zoologist in the AlpSoil Lab, mainly working with critters such as earthworms, spiders, and preferably millipedes. I conduct my research in soils at all elevations, including the lowlands, but I really love to discover the soil life in mountain forests and pastures above the treeline. This comes from my passion for hiking and mountaineering, something you are born with when you grow up in the Dolomites (South Tyrol, Northern Italy). Beside doing science, I am fascinated by all of nature. Therefore, I am also a professional hiking guide and environmentalist. *michael.steinwandter@eurac.edu

\section{JULIA SEEBER}

I am a soil ecologist in the AlpSoil Lab, interested in understanding the relationships between soil animals and their habitats, and which soil processes the animals contribute to. I like to go on field trips to see and investigate the habitats, but I also like to do experiments with the animals in the laboratory, to watch them do marvellous things such as breaking down dead plant material. My favourite soil animals are earthworms because without them, the soil ecosystem would be much less efficient. My love of mountain sports, such as skiing and hiking, is easy to combine with my love of doing science in mountains. 